\title{
Genetic Affinities Within the Herring Gull Larus argentatus Assemblage Revealed by AFLP Genotyping
}

\author{
Peter de Knijff,,${ }^{1,2}$ Frank Denkers, ${ }^{3}$ Norman D. van Swelm, ${ }^{1}$ Martin Kuiper, ${ }^{3}$ on Behalf of the Port of \\ Rotterdam Gull Study Group

\footnotetext{
${ }^{1}$ MGC-Department of Human and Clinical Genetics, Leiden University Medical Center, P.O. Box 9503, 2300 RA Leiden, The Netherlands

${ }^{2}$ Stichting Ornthologisch Station Voorne, Schepenenweg 26, 3233 CL Oostvoorne, The Netherlands

${ }^{3}$ KeyGene N.V., P.O. Box 216, 6700 AE Wageningen, The Netherlands
}

Received: 27 January 2000 / Accepted: 18 September 2000

\begin{abstract}
To date, the taxonomic status of circumpolar breeding populations of the Herring Gull Larus argentatus, the Lesser Black-backed Gull Larus fuscus, and the closely related Yellow-legged Gull Larus cachinnans has been based on differences or similarities in phenotype, morphology, and feeding and premating behavior. To shed some new light on the many taxonomic uncertainties surrounding these taxa, we describe the results of a large DNA study based on comparing the distribution of 209 biallelic markers among 109 gulls, representing 11 gull taxa of the Herring Gull assemblage and the Common Gull Larus canus. A detailed phylogenetic analysis failed to show clustering of individuals into groups representing either geographic origin or phenotype. Alternatively, birds were grouped into taxa defined on the basis of phenotype and geographic origin or phenotype alone. Genetic analyses revealed significantly different genetic distances between all pairs of taxa. However, based on these genetic distances, again no consistent phylogenetic tree could be constructed. Analysis of molecular variance indicated that about $77 \%$ of the total genetic variability among these gulls could be explained by within-taxon differences. Only $23 \%$ of the total genetic variability was due to genetic differences between taxa, irrespective of their species or subspecies status. Although this seems to challenge the current taxonomic treatment of the herring gull assemblage, our re-
\end{abstract}

Correspondence to: Peter de Knijff, Ph.D.; email: p.de_knijff@ lumc.nl sults are too premature and too incomplete to recommend a drastic change.

Key words: Phylogeny - Larus - Herring Gull assemblage - AFLP - Populations - Analysis of molecular variance (AMOVA)

\section{Introduction}

Understanding the taxonomic status of the various circumpolar breeding species of the Herring Gull Larus argentatus assemblage is one of the most complex and challenging problems in avian taxonomy (Dwight 1925; Kist 1961; Mayr 1963, Barth 1968, 1975; Haffer 1982; Cramp and Simmons 1983). Within the western Palearctic this assemblage harbors at least 14 gull taxa (the term "taxon" is used here to represent both currently recognized species and subspecies), including the Lesser Black-backed Gull Larus fuscus and the closely related, more southernly breeding Yellow-legged Gull Larus cachinnans. These taxa are recognized on the basis of differences in behavior, phenotype, and morphology (Haffer 1982). Clearly at odds with this apparent phenotypic differentiation are the results of two genetic studies, using a limited number of polymorphic allozyme loci (Snell 1991; Johnson 1985). Both studies revealed very little genetic differentiation between taxa, purportedly due to a recent common ancestry and/or high levels of gene flow. Several authors postulated that all extant taxa 


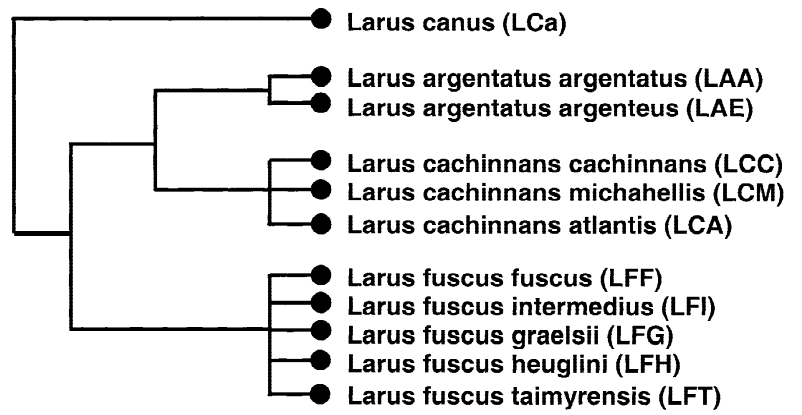

Fig. 1. Phylogeny of the Herring Gull assemblage as proposed by Haffer (1982). This phylogeny is based on differences in behavior, blometry, molting strategy, migration patterns, and plumage.

of this Herring Gull assemblage are the result of a complex and rapid speciation process, which began at the onset of the last Ice Age and was finished shortly thereafter, approximately 10,000 years ago (Barth 1968, 1975; Voipio 1993). Mayr (1963), presented the geographical distribution of these gull taxa as a classical example of a ring-species complex where the two sympatric species ( $L$. fuscus and L. argentatus) are the terminal links of the circumpolar chain. He postulated that all current taxa derive from four Pleistocene refugia. At present, most taxa seem reproductively isolated. Only during colonization of new areas does hybridization occur frequently, sometimes even leading to fertile offspring of the heterogametic sex-i.e., females in birds (van Swelm, unpublished results). In one well-studied case hybridization between L. fuscus and L. argentatus stopped as soon as L. fuscus became settled (Tinbergen 1953). However, hybridization between $L$. cachinnans with both $L$. fuscus and $L$. argentatus is still frequently observed 15 years after the initial settling of $L$. cachinnans in The Netherlands (van Swelm 1998, 2000; contra Yésou 1991).

We anticipated that if the phenotypic and behavioral differences between these taxa were indeed the result of a process of rapid reproductive isolation, slowly evolving lineage markers such as the commonly used mitochondrial cytochrome $b$ gene would not display significant genetic differentiation (cf. Crochet et al. 2000; contra Wink et al. 1994). Recently, it has been shown that an AFLP-locus based phylogeny corresponded closely with differences in phenotypes among Lake Malawi cichlid fish (Albertson et al. 1999). For this reason, and to reduce the influence of genetic drift, differential introgression, and skewed sex-dependent colonization effects (for which all mtDNA-based polymorphisms are very sensitive), we decided to analyze the genetic contribution of both sexes by means of the recently developed AFLP method (Vos et al. 1995). Genotypes of 209 autosomal codominant inherited biallelic AFLP loci were obtained in 106 birds belonging to 11 Herring Gull taxa and three Common Gulls Larus canus. As such, this study describes the first large-scale DNA-based analysis specifically focusing on this notoriously complex-but at the same time fascinating - group of avian taxa.

\section{Methods}

\section{Sample Collection}

We largely follow the nomenclature of gull taxa as proposed by Haffer (1982) (Fig. 1). Over a period of 10 years, blood samples were collected at 14 sites, all close to or at a breeding colony (Table 1) by local experts to avoid identification errors. Samples were collected in $70 \%$ ethanol or EDTA and transferred to the Leiden University Medical Center as soon as possible. DNA was isolated by means of standard phenol/chloroform extraction. We obtained DNA of sufficient quality for the purpose of this study from 109 birds: 106 samples from 11 gull taxa of the Herring Gull assemblage and 3 samples of a smaller gull species, the Common Gull Larus canus, which we included as an outgroup in a number of analyses.

\section{AFLP Analysis}

The analysis of amplified fragment length polymorphisms (AFLP) allows the detection of RFLPs in genomes with unknown sequence structures (Vos et al. 1995). Essentially, AFLP is based on (i) restriction enzyme digestion of genomic DNA, (ii) ligation of the digested fragments with specific adapters and selective amplification by means of PCR, and (iii) gel analysis of the amplified fragments. For the present study AFLP reactions were carried out using the enzyme combination EcoRI and Taql. Standard AFLP adapters for these restriction sites were ligated to the DNA fragments and AFLP primers for both enzymes were used in subsequent amplification reactions. The detection and subsequent analysis of the fragments closely followed the procedures outlined in detail previously (Vos et al. 1995). Following these protocols we obtained genotype scores of 209 distinct loci.

\section{Statistical and Phylogenetic Analysis}

After AFLP analysis two genetic scores were constructed. The first represents the genotype of each locus. Thus for each individual, 209 genotype scores were obtained-0/0, 0/1, and $1 / 1$ - which, in analogy with conventional RFLP scores, represent the absence $(0)$ or presence (1) of a particular band. Since AFLP alleles, like RFLP alleles, are codominant inherited, one can distinguish two homozygous and a single heterozygous genotype. Based on these genotypes we also derived a haplotype score, $0-1-$ ?, where 0 indicates the total absence of an AFLP fragment (genotype 0/0), 1 represents the presence (heterozygous or homozygous) of an AFLP fragment (genotypes 0/1 and 1/1), and ? represents unresolved scores (genotypes 0/?, 1/?, and ?/?). This haplotype score underestimates the total amount of genetic information present in our data set, thereby providing a conservative estimate.

First, all haplotype scores were analyzed by means of the PUZZLE v4.0 package (Strimmer and von Haeseler 1996, 1997). A single complete maximum likelihood-based tree resolving analysis with 100 intermediate trees on this total data set was performed. [This analysis took $96 \mathrm{~h}$ using a PC with a Pentium II MMX (233-MHz) processor; increasing the number of intermediate trees to 1000 would require an unrealistic $>5000 \mathrm{~h}$.] The resulting tree was drawn using TreeView v1.5.2 (Page 1998) and is illustrated in Fig. 2.

Second, we employed an analysis of molecular variance (AMOVA) by means of ARLEQUIN v1.1 (Excoffier et al. 1992; Schneider et al. 1997). This allows the partitioning of the total amount of genetic variation present in any data set into a number of hierarchical ordered components representing (1) genetic variance due to differences between individuals within populations, (2) genetic variance due to differences between populations within groups, and (3) genetic variation due to differences between groups. From a taxonomic perspective, this could be translated to differences between individuals of the same 
Table 1. Information on the sampling locations and the taxa included in this gull DNA study

\begin{tabular}{|c|c|c|c|c|c|}
\hline \multicolumn{4}{|c|}{ Sampling location information } & \multicolumn{2}{|l|}{ Taxon information } \\
\hline No & Name (country) & Latitude & Longitude & Name (code) & Number of samples \\
\hline 1 & Taimyr (Russia) & +74.07 & +86.29 & Taimyr Gull, Larus fuscus taimyrensis (LFT) & 6 \\
\hline 2 & Kanin (Russia) & +67.80 & +44.14 & Heuglins Gull, Larus fuscus heuglini (LFH) & 10 \\
\hline 3 & Kandalaksha (Russia) & +67.00 & +32.30 & Herring Gull, Larus argentatus argentatus (LAA) & 5 \\
\hline 4 & East Finland & +61.50 & +28.50 & Baltic Gull, Larus fuscus fuscus (LFF) & 3 \\
\hline $5 \mathrm{a}$ & West Finland & +60.07 & +25.25 & Herring Gull, Larus argentatus argentatus (LAA) & 7 \\
\hline $5 b$ & West Finland & +60.07 & +25.25 & Baltic Gull, Larus fuscus fuscus (LFF) & 4 \\
\hline 6 & West Norway & +58.03 & +6.40 & Lesser Black-backed Gull, Larus fuscus intermedius (LFI) & 10 \\
\hline $7 \mathrm{a}$ & Maasvlakte (The Netherlands) & +51.51 & +4.03 & Common Gull, Larus canus (LCa) & 3 \\
\hline $7 \mathrm{~b}$ & Maasvlakte (The Netherlands) & +51.51 & +4.03 & Herring Gull, Larus argentatus argenteus (LAE) & 8 \\
\hline $7 \mathrm{c}$ & Maasvlakte (The Netherlands) & +51.51 & +4.03 & Lesser Black-backed Gull, Larus fuscus graellsii? (LF?) & 10 \\
\hline 8 & West England & +53.30 & -2.34 & Lesser Black-backed Gull, Larus fuscus graellsii (LFG) & 6 \\
\hline 9 & Faroe Islands & +62.14 & -6.37 & Lesser Black-backed Gull, Larus fuscus graellsii (LFG) & 5 \\
\hline 10 & Iceland & +64.05 & -21.59 & Lesser Black-backed Gull, Larus fuscus graellsii (LFG) & 9 \\
\hline 11 & Berlenga Isles (Portugal) & +39.25 & -9.28 & Atlantic Gull, Larus cachinnans atlantis (LCA) & 5 \\
\hline 12 & Gibraltar (Spain/England) & +36.07 & -5.17 & Yellow-legged Gull, Larus cachinnans michahellis (LCM) & 6 \\
\hline 13 & Essaouira (Morocco) & +31.32 & -9.45 & Atlantic Gull, Larus cachinnans atlantis (LCA) & 5 \\
\hline 14 & Ukraine & +46.24 & +32.03 & Steppe Gull, Larus cachinnans cachinnans (LCC) & 7 \\
\hline
\end{tabular}

a The Lesser Black-backed Gull race in The Netherlands could be LFG, but LFI gene flow cannot be excluded based on plumage details: hence its uncertain status.

subspecies, between subspecies within species, and between species. As such, this allows the testing of any a priori taxonomical hypothesis looking for genetic differentiation between species and/or subspecies. Between genetically sufficiently isolated but related taxa, the majority of the genetic variance would be expected to be found between species, less so between subspecies, and little genetic variance between individuals of the same subspecies. The haplotype scores were grouped into a variable number of taxa on the basis of generally accepted phenotypic and/or geographic criteria as proposed by Haffer (1982) (Fig. 1, Table 1). By means of AMOVA we tested a number of hypotheses. The resulting decomposition of the variance components representing the various genetic variance estimates is summarized in Table 2. By means of AMOVA we also estimate an $F_{\text {st }}$ analogue, $\phi_{\text {st }}$, which not only considers differences in haplotype score frequencies, but also includes molecular differences between individual haplotype scores. On the basis of the pairwise $\phi_{\mathrm{st}}$ distance matrix, an UPGMA tree was made using the UPGMA option contained in the NEIGHBOR routine included in PHYLIP v3.57c (Felsenstein 1995) and TreeView v1.5.2 (Page 1998) (Fig. 3A). Bootstrap supports were obtained by creating, from the original haplotype scores, 100 randomized sets of haplotype scores by means of the SEQBOOT routine included in PHYLIP v3.57c. Each of these 100 sets was again analyzed by means of ARLEQUIN v1.1, the resulting 100 pairwise $\phi_{\mathrm{st}}$ distance matrices were combined into a single file, analyzed as above, and the resulting 100 trees were analyzed by means of the CONSENSE routine, also included in PHYLIP v3.57c. Finally, again using ARLEQUIN v1.1, we estimate the number of pairwise differences (often referred to as the mismatch distribution) between all originally observed haplotype scores (Fig. 4).

Since the haplotype scores represent an underestimate of the true genetic variability in our data set, we also analyzed the genotypic scores. Using GDA v1.0 (d12) (Lewis and Zaykin 1999), GENEPOP v3.1c (Raymond and Rousset 1995), and ARLEQUIN v1.1, a number of descriptive statistics were obtained for all loci in all taxa (Table 3). These include, for each taxon, $H_{\mathrm{e}}$, the expected heterozygosity, $H_{\mathrm{o}}$, the observed heterozygosity, $N_{\mathrm{m}}$, the estimated number of migrants per generation between taxa, $F_{\text {is }}$, Wright's inbreeding coefficient, and the allele frequency distributions. In addition, we calculated, across all loci and all taxa again, $F_{\text {is }}$ (inbreeding within taxa), $F_{\text {it }}$ (overall inbreeding), and the coancestry coefficient $F_{\text {st }}$, which provides an estimate of interspecific genetic differentiation. From the allele frequencies of all 209 loci, we calculated Nei's (1972) genetic distance by means of the
GENDIST routine from PHYLIP v3.57c. The resulting distance matrix was analyzed exactly as the haplotype score-based $\phi_{\text {st }}$ matrix with one difference: the bootstrap supports were obtained on the basis of 1000 SEQBOOT-generated sets of allele frequencies. The resulting tree is illustrated in Fig. 3B.

\section{Results}

A maximum likelihood-based phylogenetic tree connecting all individuals on the basis of the individual haplotype scores was constructed by means of PUZZLE v4.0 (Fig. 2). No consistent grouping of individuals into distinct clusters (e.g., representing the sampling locations or phenotype) was observed. In contrast, most individuals form a distinct branch of their own, and all branches seem to descend from a single shared ancestor in a starlike fashion. This strongly suggests a relatively recently shared common ancestry between all herring gulls and/or a rapid expansion. This is confirmed by the mismatch distribution (Fig. 4). The unimodal shape of this number of pairwise difference distribution is a good indication of a single-exponential population expansion.

We subsequently grouped all birds into a number of taxa on the basis of their phenotype and/or geographical origin. On the basis of the haplotype scores, the genetic distance $\left(\phi_{\mathrm{st}}\right)$ between all pairs of taxa was estimated by means of AMOVA (Table 2). When birds were grouped into a single group containing 17 gull taxa identified by the combination of sampling location and phenotype, about $78.4 \%$ of the total genetic variability present among all birds could be attributed to genetic differentiation within taxa, whereas the remaining $21.6 \%$ was due to genetic differences between taxa. A similar partitioning was obtained when birds were allocated to 12 


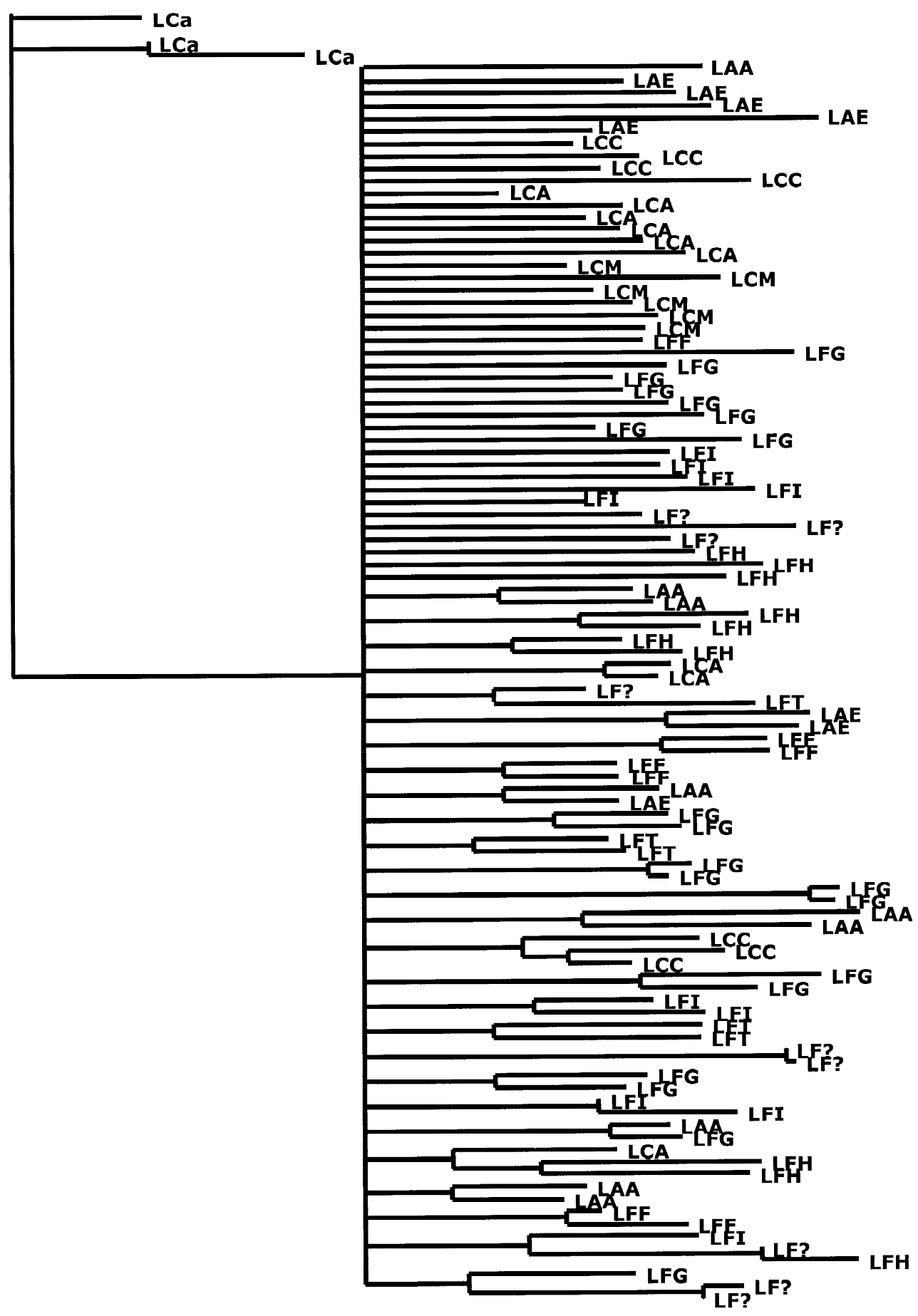

Fig. 2. A quartet puzzling based maximum-likelihood tree of all 109 gulls based on the binary AFLP haplotype scores. Branch supports (most of which are below 50\%) are removed for clarity.

taxa solely on the basis of their phenotype. We also analyzed a number of more detailed models representing several previously proposed taxonomic orderings. In all these alternative models the within-taxon genetic variance explained about $77 \%$ of the total genetic variance, and the remaining $23 \%$ was due to the between-taxa, within-groups and the between-groups components.

Again, this indicates that among our birds, despite their geographical and phenotypical differentiation, no specific genetically well-defined taxa could be identified. Thus, on the basis of our haplotype score-derived AMOVA analysis, no clear hierarchical difference in the between-species and between-subspecies contributions could be detected, although when the two most extreme models were compared-model 3 with four Herring Gull species and model 6 with seven species-the latter model did indicate a slightly better species-subspecies structure. 
Table 2. Results of analysis of molecular variance (AMOVA) based on haplotype scores and genotypes (in parentheses) of 209 AFLP loci among all 109 gulls

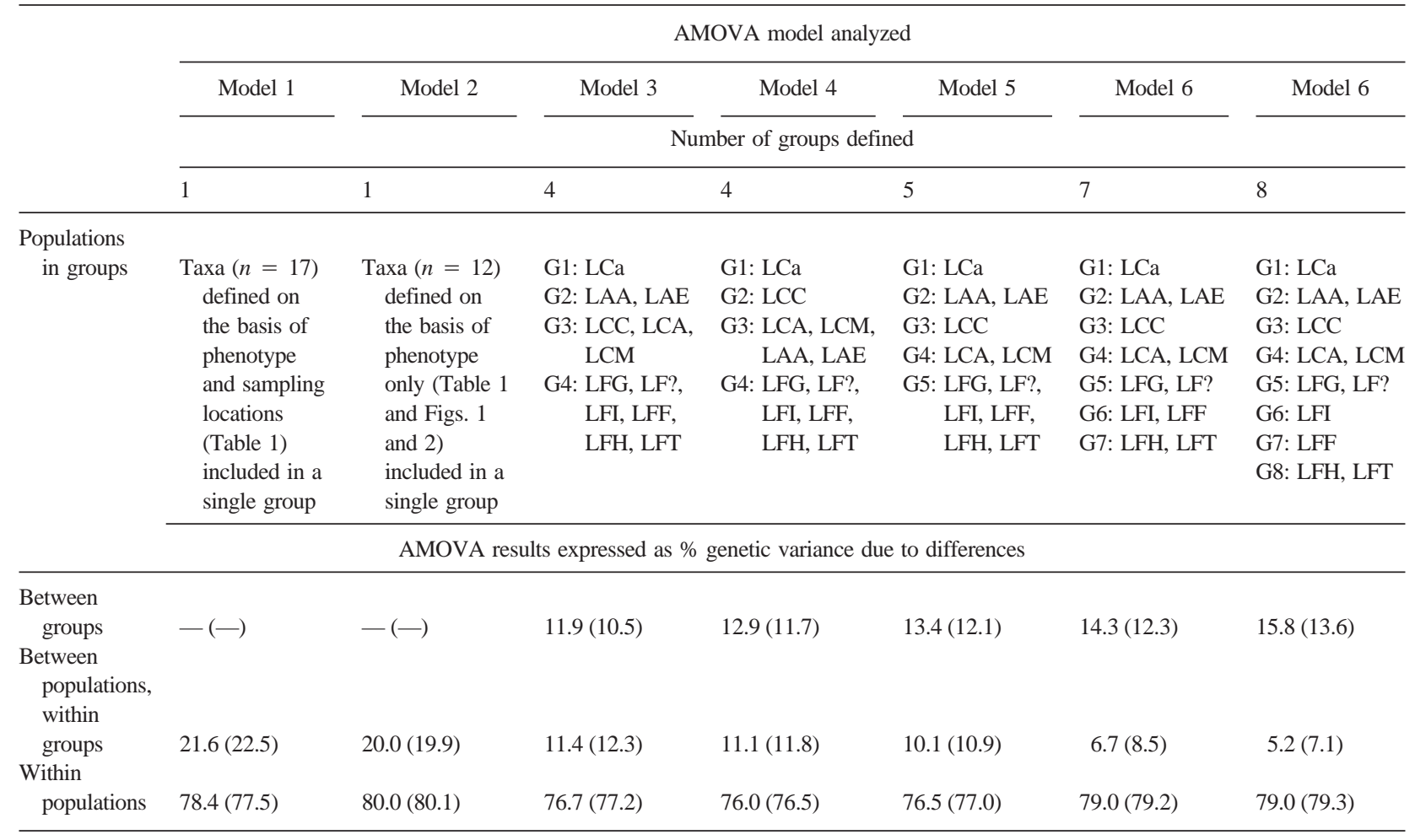

It could be argued that the AFLP haplotype score, because of its recessive character, underestimates the genetic information content. Therefore, we repeated all analyses using the AFLP genotypes. Table 3 summarizes a number of descriptive statistics. Very striking is the difference between $H_{\mathrm{e}}$ and $H_{\mathrm{o}}$. For all taxa $H_{\mathrm{o}}$ was less than $50 \%$ of $H_{\mathrm{e}}$, indicating a marked reduction in the number of heterozygotes. This and the high $F_{\text {is }}$ (inbreeding coefficient) values are good indications of a high proportion of birds returning to the same breeding colony. On the other hand, the rather high $N_{\mathrm{m}}$ values and the very few private alleles $\left(N_{\mathrm{pa}}\right)$ observed (13 in total) indicate high levels of gene flow. This is also confirmed by the three coefficients, $F_{\text {is }}(0.61), F_{\text {it }}(0.67)$, and $F_{\text {st }}$ (0.16) (not shown), which are all highly significant indicators of little geographic and interspecific differentiation. These results are confirmed by our hierarchical AMOVA (Table 2), which shows near-identical results when the genotype-based data are compared with the haplotype score analyses.

Two UPGMA trees were built on the basis of the AMOVA-derived pairwise $\phi_{\text {st }}$ distances. One represents the genetic distances estimated from the haplotype scores. The other represents Nei's (1972) genetic distance, based on the genotypes (Figs. 3A and B). Both trees have a structure closely corresponding with the species/subspecies hierarchy proposed by Haffer (1982) (Fig. 1). All Lesser Black-backed Gull taxa (L.f. fuscus, L. f. intermedius, L. f. graellsii, L. f. heuglini, and L. f. taimyrensis) form a single major clade, whereas the two
Herring Gulls (L.a. argenteus and L. a. argentatus) and two Yellow-legged Gull taxa (L. C. michahellis and L. c. atlantis) form subclades in a second major clade. The Steppe Gull L. c. cachinnans is paraphyletic to all other large gulls and closest to the outgroup (Common Gull $L$. canus). Only three branches, those connecting (1) L. $f$. graellsii from Iceland, the Faeroe Islands, and England with Dutch L. f. graellsii, (2) L. a. argenteus and L. a. argentatus, and (3) L. c. michahellis and L. c. atlantis, have support values $>90 \%$. Especially the support for the bifurcation of the two major groups is rather low in both trees (42 and 30\%). This suggests that these taxa are extremely closely related to one another and that a complete and reliable phylogenetic ordering of these gulls on the basis of the present genetic information is impossible.

\section{Discussion}

In this study we describe a detailed genetic analysis of western Palearctic taxa of the Herring Gull Larus argentatus, the Lesser Black-backed Gull Larus fuscus, and the Yellow-legged Gull Larus cachinnans. These birds, representing the notoriously complex Herring Gull assemblage, have been the subject of heated debates throughout the past century. Taxa have been shifted between almost all possible taxonomic statues off and on (Dwight 1925; Kist 1961; Barth 1968, 1975; Haffer 1982; Cramp and Simmons 1983). Invariably, new in- 


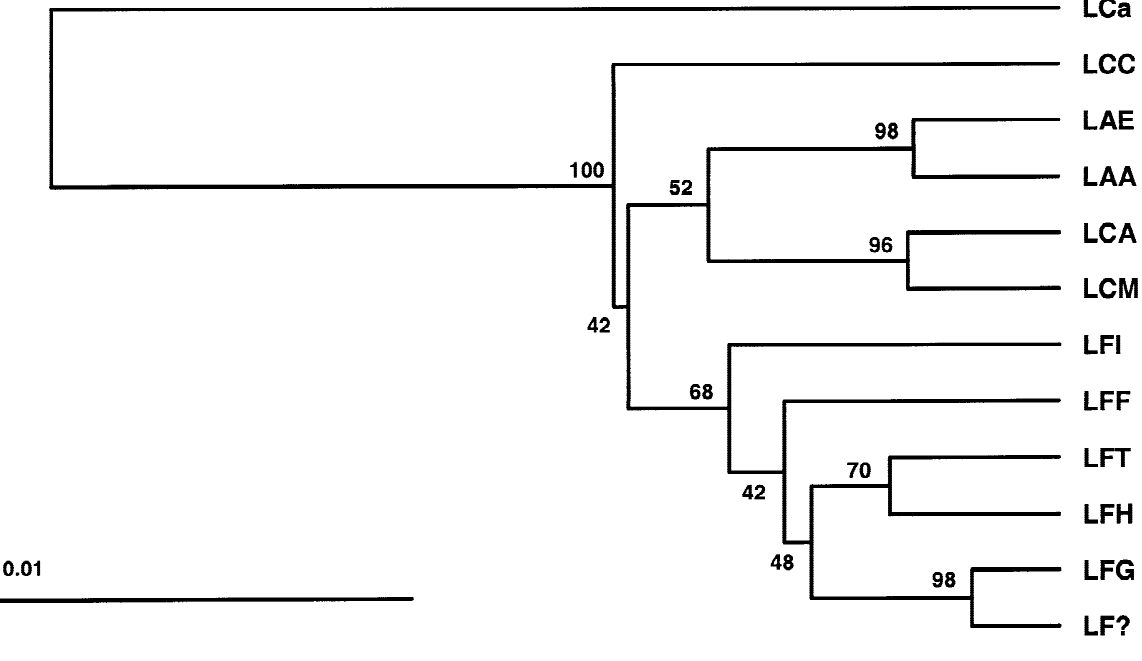

3B

0.01

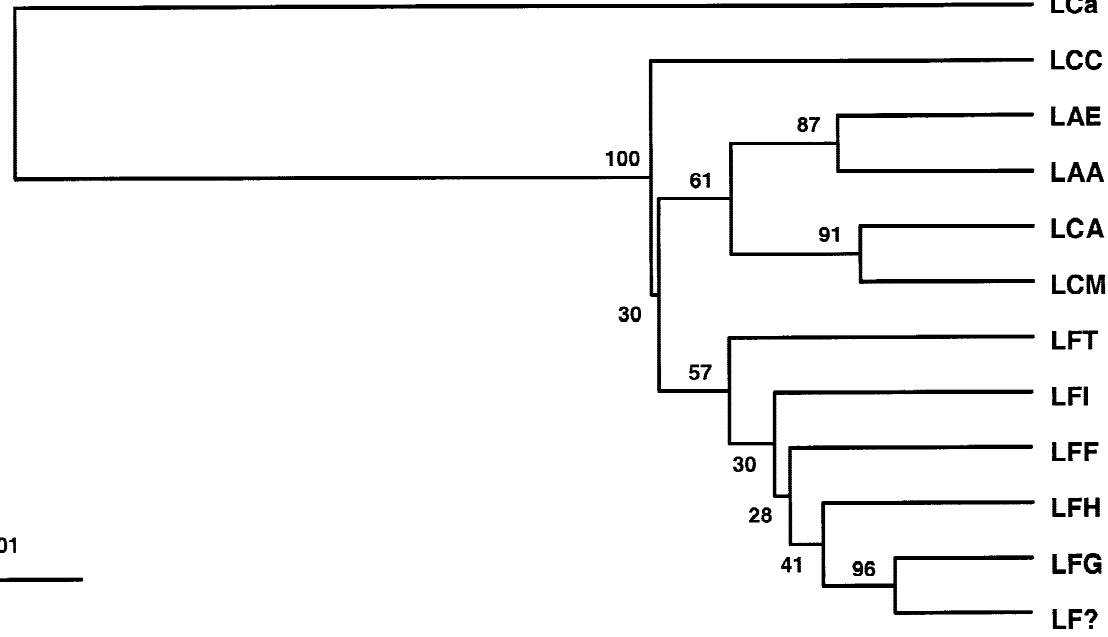

Fig. 3. A UPGMA tree based on the AMOVA-derived $\phi_{\text {st }}$ distance between pairs of gull populations based on the AFLP haplotype scores. Numbers of supporting bootstrap replications (as a percentage of 100 replicates) are indicated to the left of bifurcations. B UPGMA tree based on Nei's genetic distance between pairs of gull populations based on the AFLP allele frequencies. Numbers of supporting bootstrap replications (as a percentage of 100 replicates) are indicated to the left of bifurcations.

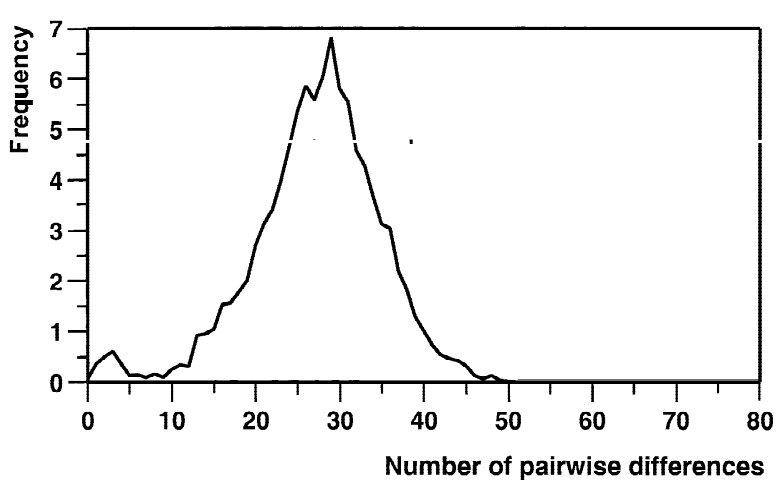

Fig. 4. Mismatch distribution showing the number of pairwise differences between the 106 binary AFLP haplotype scores of the Herring Gull assemblage. The scores of the three Common Gulls were excluded from this analysis.

sights resulting from comparative studies encompassing differences and/or similarities in phenotype and various behavioral aspects immediately resulted in a new taxonomic rearrangement. Taxa are even being declared spe- cies or completely removed from the taxonomic landscape solely on the basis of personal preference (Sangster et al. 1999). Therefore, it seemed wise to seek help by means of molecular methods. We speculated that if the phenotypic and behavioral differences between these taxa were indeed the result of reproductive isolation, this could be reflected by corresponding genetic differentiation.

We anticipated that an mtDNA-based analysis would not render sufficiently reliable information for a number of reasons. Because of the lack of any published autosomal genetic sequence information on large gulls, we used the recently published AFLP method allowing the analysis of many biallelic loci in genomes with an unknown sequence composition (Vos 1995). In addition, AFLPs have the advantage of representing genetic information from both sexes. Thereby, phenomena such as differential introgression, lineage sorting, and selective transmission due to skewed migration patterns, which 
Table 3. Descriptive statistics based on genotypes of 209 AFLP loci among 109 gulls $^{\mathrm{a}}$

\begin{tabular}{lrrllllll}
\hline Population & \multicolumn{1}{c}{$N_{\text {ind }}$} & \multicolumn{1}{c}{$M_{\mathrm{ss}}$} & $P$ & $H_{\mathrm{e}}$ & $H_{\mathrm{o}}$ & $N_{\mathrm{m}}$ & $F_{\text {is }}$ & $N_{\text {pa }}$ \\
\hline LCa & 3 & 2.87 & 0.20 & 0.10 & 0.04 & 0.6 & 0.68 & 2 \\
LAA & 12 & 10.07 & 0.58 & 0.19 & 0.06 & 2.5 & 0.70 & 3 \\
LAE & 8 & 7.39 & 0.45 & 0.17 & 0.06 & 2.0 & 0.66 & 1 \\
LCC & 7 & 6.55 & 0.39 & 0.15 & 0.06 & 1.7 & 0.60 & 2 \\
LCA & 10 & 7.70 & 0.38 & 0.15 & 0.06 & 2.3 & 0.61 & - \\
LCM & 6 & 5.59 & 0.31 & 0.12 & 0.06 & 1.6 & 0.56 & - \\
LF? & 10 & 9.36 & 0.59 & 0.19 & 0.07 & 3.2 & 0.63 & - \\
LFG & 20 & 17.28 & 0.68 & 0.19 & 0.09 & 2.9 & 0.53 & 4 \\
LFI & 10 & 8.91 & 0.50 & 0.17 & 0.07 & 2.2 & 0.60 & 1 \\
LFF & 7 & 6.64 & 0.47 & 0.17 & 0.07 & 2.4 & 0.62 & - \\
LFH & 10 & 9.15 & 0.57 & 0.19 & 0.07 & 2.8 & 0.62 & - \\
LFT & 6 & 5.59 & 0.49 & 0.19 & 0.07 & 2.2 & 0.63 & - \\
\multicolumn{1}{c}{ Average } & 9.1 & 8.10 & 0.47 & 0.17 & 0.07 & 2.2 & 0.62 & \\
\hline
\end{tabular}

${ }^{\text {a }} N_{\text {ind }}$, number of individuals analyzed; $M_{\mathrm{ss}}$, mean sample size over all loci; $P$, proportion of polymorphic loci; $H_{\mathrm{e}}$, expected heterozygosity; $H_{\mathrm{o}}$, observed heterozygosity; $N_{\mathrm{m}}$, average estimated number of migrants between taxon $X$ and all other taxa; $F_{\text {is }}$, inbreeding coefficient within taxa; $N_{\text {pa }}$, number of private alleles for each taxon. Estimates were obtained by GDA v1.0 (d12) except $N_{\mathrm{m}}$, which was obtained by ARLEQUIN v1.1.

can seriously distort true genetic relations between closely related taxa, can be avoided.

Our analyses indicate high levels of gene flow, with average $N_{\mathrm{m}}$ values varying between 0.6 and 3.2, but with values up to 8.3 for some population pairs. We also observed very few private alleles (only 13 of 418), and only $23 \%$ of the total genetic variance could be explained by genetic differentiation between taxa. These observations all indicate a minimal genetic divergence between closely related taxa. On the other hand, we observed very high inbreeding coefficients and significantly reduced heterozygosity values, both suggesting genetic isolation between taxa. These seemingly contradicting observations could be due to a combined effect of a recent common ancestry and a high breeding-site fidelity among these minimally divergent taxa. Our data confirm the results of two allozyme studies, which included partially the same taxa (Snell 1991; Johnson 1985). These authors also reported very low average heterozygosities and little interspecific differentiation. Only if we ignore the weak statistical support values does the topology of our UPGMA trees closely match the phylogenetic ordering as proposed by Haffer (1982).

How can we reconcile the little genetic differentiation with the marked phenotypical differences and almostcomplete reproductive isolation? Two models could explain this apparent discrepancy between phenotype and genotype in these gulls. The first model suggests that these birds have not yet completed an ongoing process of speciation. An early geographical isolation, before the last glacial period in Europe, was sufficiently long ago to result in the subtle phenotypical variability and nearcomplete reproductive isolation, but too recent to create a sufficient overall genetic differentiation between all the taxa when many recombining loci are analyzed. Also, the recent population expansions of some of these taxa could have forced many individual birds to cross the species boundaries, as reflected by the relative high $N_{\mathrm{m}}$ values (up to 8.3; not shown) between all taxon pairs except those involving the outgroup (and regularly observed in the field!).

The second model postulates that extant gull taxa are representatives of a single species with various forms sharing a recent common ancestry, explaining their close genetic affinities. The phenotypical variability of these forms could then be explained by various degrees of hybridization between a number of original founding populations. This must have occurred on different time scales and/or at different phases of environmental adaptation. The latter model was predicted by Barth (1968), based on phenotypic and morphological differences, and is not unlike the genetic history of the Noctule Bat ( $\mathrm{Nyc}$ talus noctula) or our own human species. In both cases about $70-80 \%$ of the total genetic variability could be explained by genetic differences within geographically structured populations which spread throughout Europe shortly after the last Ice Age (Petit et al. 1999; Barbujani et al. 1997). At odds with Barth's hypothesis, proposing the Baltic Gull L. f. fuscus as the most likely ancestral taxon, is our finding suggesting that the Steppe Gull L. $c$. cachinnans is the oldest taxon of this assemblage. Although the bootstrap support for the paraphyletic status of this taxon does not exceed 50\%, this seems to support the suggestion of Voipio (1993) that the Steppe Gull L. c. cachinnans is the oldest taxon in the Herring Gull assemblage. According to the ring-species concept (Mayr 1963), all extant Herring Gulls descend from four Pleistocene refugia, the oldest of which was found in the Aralo-Caspian area, where the Steppe Gull L. c. cachinnans still breeds. Although our AFLP data do not suggest a number of different founder populations, one could argue that the time span between the Pleistocene settling of three refugia out of the Aralo-Caspian founder population and the post-Glacial dispersal of modern Herring Gulls was too short to be detected by our loci. Hence, on the basis of our data, Mayr's hypothesis cannot be rejected.

Before deciding which model is favored, a more central question has to be answered: Can AFLP data and/or the AMOVA models be used to identify species limits? It has already been shown that AFLP loci can be used to obtain detailed insight into the evolutionary history of closely related species (Albertson et al. 1999), leaving little doubt about this first point. On the other hand, AMOVA has not yet been used routinely to explore phylogeographic and evolutionary hypothesis. We know of only one other avian AMOVA: the mtDNA-sequence study among races of the Dunlin (Calidris alpina) (Weenink et al. 1996). This study is even more interesting because it involves a similar number of closely re- 
lated taxa, which have a geographical (circumpolar) breeding distribution and evolutionary history similar to those of our gull taxa. Among the Dunlin races, an mtDNA-based AMOVA revealed that about $70 \%$ of the total genetic variation could be attributed to differences between the taxa, and only about $30 \%$ was due to differences within taxa. Thus, AMOVA can reveal distinct genetic differentiation between closely related and recently derived avian taxa. Furthermore, it could be argued that, because the Dunlin AMOVA results were based on mtDNA-sequence information (which normally displays a markedly faster genetic divergence compared with autosomal loci), they are not in conflict with our results, simply because of the difference in the choice of loci. Hence, our finding of very little genetic differentiation between the gull taxa does not necessarily preclude acceptance of the first model but cannot reject the second one either.

On the basis of the currently available genetic data, we favor a hybrid between both models. Although the phylogeographic history of the Herring Gull assemblage, as hypothesized by Barth (1968), Mayr (1963), and Voipio (1993), is probably not entirely correct, it is probably not far off either. All three authors propose the AraloCaspian area as the most ancient region of origin of modern Herring Gulls. This corresponds with our results indicating that the Steppe Gull L. c. cachinnans, which still breeds in this area, could be the oldest taxon of this assemblage.

One could argue that all current sympatric-breeding, phenotypically distinct Herring Gull taxa are reproductively isolated and therefore, acknowledging the biological species concept, should be considered separate species. However, our AMOVAs did not reveal a distinct differentiation between the currently recognized species and subspecies. Because of this, a choice between the two extremes (three vs seven species) cannot be made. Therefore, we think it is wise to adopt the most conservative model, treating these taxa as three distinct species, L. argentatus, L. cachinnans, and L. fuscus, a conclusion which was proposed by Haffer in 1982 (see Fig. 1) and is still largely followed by most authors.

Acknowledgments. This study would not have been possible without the unconditional support of the following members of the Port of Rotterdam Gull Study Group: The Netherlands-Drs. Mark van Leeuwen, Fred Cottaar, and Gerrit Goedhart; England-Peter Stewart; Denmark-Eddie Fritze, Dr. Pelle Harild Andersen, and Kjeld T. Pedersen; Poland-Monica and Dr. Dariusz Bukacinski; Spain-Marc Bosch; Lithuania, Dr. Pranias Mierauskas; Russia-Dr. V.V. Bianki and Valery Buzun; Finland-Dr. Martti Hario and Risto Juvaste; Norway_-Tor Oddvar Hansen and Nils Helge Lorentzen; Gibraltar-Dr. John Cortes; Iceland-Arnor Sigfusson; Faeroe Islands—Jens Kjeld Jensen; Ukraine—Dr. Antonina Rudenko; Germany—Drs. Dorit Liebers, Andreas Helbig, Arndt von Haeseler, and Kurbinian Strimmer; and Portugal-Dr. Lurdes Morais. Some of them collected blood samples at the most impossible places, sometimes under hostile conditions. Others provided invaluable statistical support.

\section{References}

Albertson RC, Markert JA, Danley PD, Kocher TD (1999) Phylogeny of a rapidly evolving clade: The cichlid fishes of Lake Malawi, East Africa. Proc Natl Acad Sci USA 96:5107-5110

Barbujani G, Magagni A, Minch E, Cavalli-Storza LL (1997) An apportionment of human DNA diversity. Proc Natl Acad Sci USA 94:4516-4519

Barth EK (1968) The circumpolar systematics of Larus argentatus and Larus fuscus with special reference to the Norwegian populations. Nytt Mag Zool 15 (Suppl 1):1-50

Barth EK (1975) Taxonomy of Larus argentatus and Larus fuscus in north-western Europe. Ornis Scand 6:49-63

Cramp S, Simmons KEL (eds) (1983) The birds of the western Palearctic, Vol 3. Oxford University Press, New York

Crochet PA, Bonhomme F, Lebreton J-D (2000) Molecular phylogeny and plumage evolution in gulls (Larini). J Evol Biol 13:47-57

Dwight J (1925) The gulls (Laridae) of the world; Their plumages, moults, variations, relationships and distribution. Bull Am Mus Natl Hist 52:63-401

Excoffier L, Smouse PE, Quattro JM (1992) Analysis of molecular variance inferred from metric distances among DNA haplotypes: Application to human mitochondrial DNA restriction data. Genetics 131:479-491

Felsenstein J (1995) PHYLIP (phylogeny inference package), version $3.57 \mathrm{c}$. Distributed by the author, Department of Genetics, University of Washington, Seattle (http://evolution.genetics.washington. edu/phylip.html)

Haffer J (1982) Systematik und Taxonomie der Larus argentatus Artengruppe. In: Glutz von Blotzheim UM, Bauer KM (eds) Handbuch der Vogel Mitteleuropas, Vol 8. Akademische Verlagsgesellschaft, Wiesbaden, pp 502-515

Johnson C (1985) Biochemical variation in populations of Larus argentatus and Larus fuscus in northwestern Europe. Biol J Linn Soc 24:349-363

Kist J (1961) 'Systematische' beschouwingen naar aanleiding van de waarneming van Heuglins Geelpootzilvermeeuw, Larus cachinnans heuglini Bree in Nederland. Ardea 49:1-50

Lewis PO, Zaykin D (1999) Genetic data analysis: Computer program for the analysis of allelic data, version 1.0 (d12) (http://chee.unm. edu/gda/)

Mayr E (1963) Animal species and evolution. Harvard University Press, Cambridge, MA

Nei M (1987) Molecular evolutionary genetics. Columbia University Press, New York

Page RDM (1998) TreeView (Win32), version 1.5.2 (http:// taxonomy.zoology.gla.ac.uk/rod/rod.html)

Petit E, Excoffier L, Mayer F (1999) No evidence of bottleneck in the postglacial recolonization of Europe by the noctule bat (Nyctalus noctula). Evolution 53:1247-1258

Raymond M, Rousset F (1995) GENEPOP (version 1.2): Population genetics software for exact tests and ecumenicism. J Hered 86:248249 (version 3.1c: http://www.cefe.cnrs-mop.fr/)

Sangster G, Hazevoet CJ, van den Berg AB, Roselaar CS, Sluys R (1999) Dutch avifaunal list: Species concepts, taxonomic instability, and taxonomic changes in 1977-1998. Ardea 87:139-165

Schneider S, Kueffer J-M, Roessli D, Excoffier L (1997) Arlequin version 1.1: A software for population genetic data analysis. Genetics and Biometry Laboratory, University of Geneva, Geneva, Switzerland (http://anthropologie.unige.ch/arlequin)

Snell RR (1991) Interspecific allozyme differentiation among north Atlantic white-headed larid gulls. Auk 108:319-328

van Swelm ND (1998) Status of the Yellow-legged Gull Larus michahellis as a breeding bird in The Netherlands. Sula 12:199-202

van Swelm ND (2001) Identification of Yellow-legged Gulls. Br Birds (in press)

Strimmer K, von Haeseler A (1996) Quartet puzzling: A quartet puz- 
zling maximum-likelihood method for reconstructing tree topologies. Mol Biol Evol 13:964-969 (version 4.0: http://www.zi. biologie.uni-muenchen.de/ strimmer/puzzle.html)

Strimmer K, von Haeseler A (1997) Likelihood-mapping: A simple method to visualize phylogenetic content of a sequence alignment. Proc Natl Acad Sci USA 94:6815-6819

Tinbergen NA (1953) The Herring Gull's world. Collins, London

Voipio P (1993) Differences in ecological properties in the Herring Gull (Larus argentatus) as a basis for explaining and predicting colonization events-A case history in retrospect. Ann Zool Fennici 30:3-15

Vos P, Hogers R, Bleeker M, Reijans M, van de Lee T, Hornes M,
Frijters A, Pot J, Peleman J, Kuiper M, Zabeau M (1995) AFLP: A new technique for DNA fingerprinting. Nucleic Acids Res 23: $4407-4414$

Weenink PW, Baker AJ, Rösner H-U, Tilanus MGJ (1996) Global mitochondrial DNA phylogeography of Holarctic breeding Dunlins (Calidris alpina). Evolution 50:318-330

Wink M, Kahl U, Heidrich P (1994) Lassen sich Silber-, Weisskopfund Heringsmöwe (Larus argentatus, L. cachinnans, L. fuscus) molekulargenetisch unterscheiden? J Orn 135:73-80

Yésou P (1991) The sympatric breeding of Larus fuscus, L. cachinnans and L. argentatus in western France. Ibis 133:256-263 